\title{
Does seed size affect water stress tolerance in Quercus Leucotrichophora a. Camus at germination and early seedling growth stage?
}

\begin{abstract}
Effect of seed size on drought stress tolerance of Quercus leucotrichophora A. Camus (banj oak) was investigated at germination and early seedling growth stage. Healthy seeds of Q. leucotrichophora were collected and categorized into four size classes (small, medium, large and very large) and germinated in Polyethylene glycol (PEG 6000 ) solutions with initial osmotic potential ranging from 0 to $-0.9 \mathrm{MPa}$ at room temperature. Final germination percentages, fresh and dry weight of seedlings were measured. From obtained data, seedling vigor index, response breadth, percent weight reduction, sensitivity and drought stress tolerance were determined for different size classes. In the present study, final germination percentage, fresh and dry weight of seedlings increased with increasing seed size class and decreased with increasing drought stress level, while germination rate showed a reverse trend. Drought stress tolerance indexes in terms of germination and seedling dry weight indicated that large sized seeds were better fitted to germinate under the range of drought stress as compared to small seeds.
\end{abstract}

Keywords: Quercus leucotrichophora, drought stress, seed size, seed germination, seed vigor
Volume I Issue I - 2017

\author{
Rachita Pandey, Kiran Bargali, Bargali SS \\ Department of Botany, Kumaun University, India
}

Correspondence: Department of Botany, DSB Campus, Kumaun University, Nainital-26300I, Uttarakhand, India, Email surendrakiran@rediffmail.com

Received: March 15, 2017| Published: July 10, 2017

\section{Introduction}

Seed is a key element in plant production as it exercises a profound influence on the success or failure of both artificial and natural regeneration start with it. ${ }^{1}$ Generally, seed germination is controlled by many internal and external factors; seed size is one of them. ${ }^{2}$ It is an important parameter which influences the germination, growth and biomass of the nursery seedling and that trend leads to the future crop. ${ }^{3}$ Thus, seed size can be used to predict germination and seedling growth rates, both in the nursery and for brief period following plantation establishment. ${ }^{4}$

The seed size variation has been shown to have several important ecological implications. It may affect seed germination, ${ }^{5}$ emergence, ${ }^{6}$ seedling establishment, ${ }^{7}$ growth rate and plant size, ${ }^{8}$ survivorship, ${ }^{9}$ competitive ability and reproductive ability of adult plant. ${ }^{10}$ Several studies carried out on weeds and crops have revealed that seedling size is usually directly related with food reserves and energy content of seeds which increases with seed weight. ${ }^{8,11-13}$ However, in the case of tree species similar studies are rather few and scattered. ${ }^{14,15}$ Soil water supply is an important environmental factor controlling seed germination. ${ }^{16}$ If the water potential is reduced, seed germination could be delayed or prevented depending on the extent of its reduction. ${ }^{17} \mathrm{~A}$ large number of studies have been carried out on the effects of water stress on the germination of forest species, ${ }^{18-20}$ and it is often emphasized that the tolerance of seeds to various stresses during germination should be determined. ${ }^{21}$ This information could be helpful in understanding the adaptive strategies of seeds for germination. $^{22}$

Quercus leucotrichophora A. Camus (banj oak) is among the five evergreen oak species of the Central Himalayan forests. It is distributed between 1200-2300m elevations and serves as a 'keystone' species in the region because of its significant contribution in soil and water conservation and to sustain rural ecosystems. ${ }^{23,24}$ The wood is used as fuel and for making agricultural tools, leaves as green fodder particularly during lean periods and leaf litter as cattle bedding. Acorns (seeds) make wildlife food for animals like Macaca mulata (Monkeys) and many species of birds. These forests are important for inflow and spring recharge of water for drinking and domestic uses of local residents. In order to meet the needs, the species is being harvested at an alarming rate from the natural populations. The future of these forests depends upon the regeneration and successful establishment of seedlings. In the central Himalayan region, there are reports that $Q$. leucotrichophora is not regenerating in Nainital forest division. ${ }^{25,26} \mathrm{~A}$ large variability in seed size is common in oak species and could affect regeneration potential and seedling quality. In the present study, effect of drought stress on the seed germination was carried out to determine the effect of seed size on germination and early seedling growth in $Q$. leucotrichophora subjected to drought stress.

\section{Material and methods}

\section{Seed source}

Acorns of $Q$. leucotrichophora were collected at maturity from natural oak forest around Nainital town of Uttarakhand State, India (between $29^{\circ} 21^{\prime \prime}-29^{\circ} 24^{\prime \prime} \mathrm{N}$ latitude and $79^{\circ} 25^{\prime \prime}-79^{\circ} 29^{\prime \prime} \mathrm{E}$ longitude). After collection, seeds were brought to the laboratory in polyethylene bags, air dried and defective acorns were discarded by visual inspection. Acorn size classes were determined by mixing and spreading acorns on a table and seeds were visually separated into four size classes viz. small $\left(\mathrm{S}_{1}\right)$, medium $\left(\mathrm{S}_{2}\right)$, large $\left(\mathrm{S}_{3}\right)$, and very 
large $\left(\mathrm{S}_{4}\right)$. Length and width of 10 seeds in each size class with three replicate were also determined (Table 1).

Table I Seed size class of Q. leucotrichophora

\begin{tabular}{lll}
\hline Seed Size Class & Length $(\mathbf{c m})$ & Width $(\mathbf{c m})$ \\
\hline S I & $2.12 \pm 0.07$ & $1.00 \pm 0.13$ \\
S 2 & $2.86 \pm 0.42$ & $1.44 \pm 0.05$ \\
S 3 & $3.15 \pm 0.08$ & $2.14 \pm 0.10$ \\
S 4 & $3.72 \pm 0.07$ & $2.36 \pm 0.18$ \\
\hline
\end{tabular}

\section{Seed germination test}

Germination tests were performed in $11 \mathrm{~cm}$ diameter glass petri dishes on two layers of filter paper saturated with PEG-6000 solutions and distilled water for control. Only seeds that sank to the bottom when immersed in water were used. A technique for studying the effect of water stress on germination is to simulate stress condition using artificial solutions to provide variable water potential levels. In this study, various levels of external drought stress $(0,-0.3 \mathrm{MPa}$, $-0.6 \mathrm{MPa}$ and $-0.9 \mathrm{MPa}$ ) were produced by PEG-6000 solution. For each treatment, there were three replicate with ten seeds per treatment arranged in a completely randomized design. The germinated seeds were counted every day for 35 days following first sign of germination ${ }^{27}$ and the seeds were considered germinated if the radicle exceeded 2 $\mathrm{mm}$ in length. Cumulative germination percentage (\%) was evaluated daily and final value was obtained after 35 days. After 35 days, the fresh weight of germinated seeds was measured; after being oven dried at $60^{\circ} \mathrm{C}$ for 24 hours, the dry weights were immediately taken. The response of $Q$. leucotrichophora germination characteristics to seed size and drought stress was examined by calculating:

A. Final germination percentage

$$
\mathrm{GR}=\frac{\text { Number of Total Germinated Seeds }}{\text { Total Number of Seeds Tested }} \times 100
$$

B. Germination rate:

$\mathrm{R}=$ Number of Total Germinated Seed Day of First Count

Number of Germinated Seeds

C. Mean daily germination (MDG):

$$
\mathrm{MDG}=\frac{\text { Cumulative germination percentage }}{\text { Total Number of days }}
$$

D. Weight reduction percentage (\%):

According to each drought stress treatment, the fresh and dry weights referred to the controlled, were calculated in percent by the following equation:-

Fresh weight $(F W)$ percentage reduction:

FWPR \% $=100 \times\left[1-\left(\right.\right.$ fresh weight ${ }_{\text {drought stress }} /$ fresh weight $\left.\left.{ }_{\text {control }}\right)\right]$

Dry weight (DW) percentage reduction:

DWPR \% $=100 \times\left[1-\left(\right.\right.$ dry weight ${ }_{\text {drought stress }} /$ dry weight $\left.\left.{ }_{\text {control }}\right)\right]$

E. Seedling vigor Index (SVI): This index was determined following method. ${ }^{28}$
SVI $=$ Germination percentage $\times$ seedling dry weight

F. Relative water content (RWC): The water content respective to the fresh weight was calculated as described by. ${ }^{29}$

$$
\mathrm{RWC} \%=100 \times[(\mathrm{FW}-\mathrm{DW}) / \mathrm{FW}]
$$

G. Drought stress tolerance index: Germination stress tolerance index (GSI), and seedling dry matter stress tolerance index (DMSI) were calculated using the following formulae given. ${ }^{30}$

$\mathrm{GSI}=($ Germination percentage in stressed seeds/ Germination percentage in control) $\mathrm{x} 100$

SDSI $=($ Dry matter in stressed plants/ Dry matter in control $) \times 100$

H. Niche breadth: For each size class niche breadth was calculated using equation ${ }^{31}$ and to determine the performance of size class on a drought stress gradient. ${ }^{32}$

$$
\mathrm{B}=\frac{1}{\left(\sum_{i=1}^{s} P i 2\right) S}
$$

Where, $\mathrm{B}$ is niche breadth; $\mathrm{Pi}$ is the proportional response of size class $\mathrm{P}$ in the $\mathrm{i}^{\text {th }}$ drought stress level and $\mathrm{S}$ is the number of drought stress level. The measure ranges from 0 to 1 with 1 being a perfectly even distribution of response. The results were analyzed using analysis of variance (ANOVA). The data were analyzed for original data in case of mean daily germination and transformed value in case of percent germination.

\section{Results}

\section{Effect of seed size on germination indices}

In this experiment, germination percentage generally decreased with increasing water stress level at each size class (Figure 1A). Analysis of variance (ANOVA) indicated significant differences between seed size classes and between treatments. However, the effect of seed size class does not depend on drought stress level, hence there is no statistically significant interaction between size class and drought stress level (Appendix 1). Maximum germination was recorded in size class 4 at control $(70 \%)$ while minimum germination was recorded in size class 1 at $-0.6 \mathrm{MPa}$ stress level $(20 \%)$. At each drought stress level, seed germination increased with increasing seed size. Pair wise comparison between size classes showed that difference in germination percentage between S4 and S3 and between $\mathrm{S} 3$ and S2 were insignificant while rest of the classes showed significant difference (Appendix 2). Considering drought stress as factor, difference in germination percentage showed significant difference between control and W3 (-0.9 MPa) and between control and W2 $(-0.6 \mathrm{MPa})$ only, rest of the levels showed insignificant differences (Appendix 3). Among the four size classes, size class 1 was very sensitive to drought stress and size class 3 and 4 showed better performance against drought stress. Comparison between control and drought stress levels showed that size class 4 performed better than other three classes while size class 1 showed maximum inhibition due to drought stress (Figure 1A).

In contrast to germination percentage, the germination rate decreased with increasing seed size as well as water stress level (Figure 1B). At each size class, seed germination rate showed fluctuating pattern along the water stress gradient, the lowest germination rate in all the size classes was recorded at highest (-0.9 MPa) drought stress 
level (Figure 1B). Days taken to initiate the germination processes varied in different size classes. At control level, the minimum time taken by all the four size classes for initiation was 21 days. However, water stress showed no significant effect on emergence time. Size class 4 showed better initiations as compared to other size classes (Table 2).
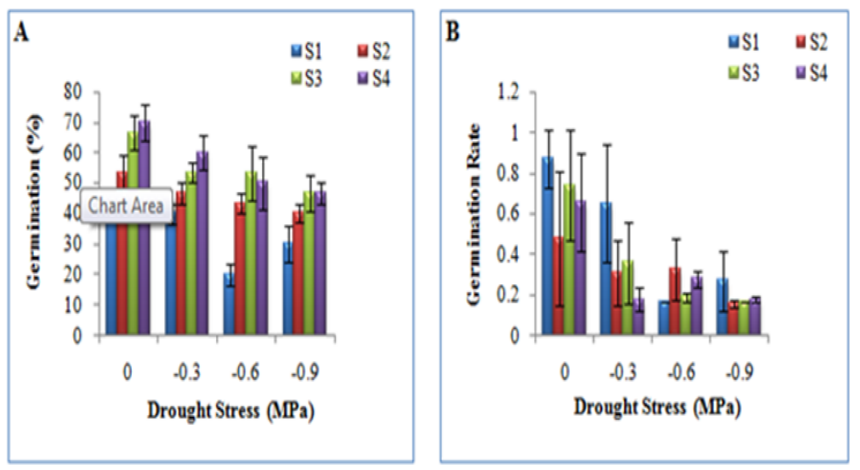

Figure I Seed germination percentage (A). Germination rate (B) in Q. leucotrichophora as affected by seed size and drought stress.

Appendix I Analysis of variance for germination of Q. leucotrichophora as affected by seed size and drought stress.

\begin{tabular}{llllll}
\hline $\begin{array}{l}\text { Source of } \\
\text { Variation }\end{array}$ & DF & SS & MS & F & P \\
\hline Size class & 3 & $4 \mid 22.92$ & 1374.31 & $15.7 \mid$ & $<0.001$ \\
Drought stress & 3 & 2422.92 & 807.64 & 9.23 & $<0.001$ \\
$\begin{array}{l}\text { Size class } x \text { drought } \\
\text { stress }\end{array}$ & 9 & 502.08 & 55.79 & 0.64 & 0.757 \\
Residual & 32 & 2800 & 87.5 & & \\
Total & 47 & 9847.92 & 209.53 & & \\
\hline
\end{tabular}

Appendix 2 Pair wise comparison (Tukey test) for factor size class.

\begin{tabular}{llllll}
\hline Comparison & Diff. of means & $\mathbf{P}$ & $\mathbf{Q}$ & $\mathbf{p}$ & $\mathbf{p}<\mathbf{0 . 0 5 0}$ \\
\hline S4 vs SI & 23.33 & 4 & 8.64 & $<0.001$ & Yes \\
S4 vs S2 & 10.83 & 4 & 4.01 & 0.037 & Yes \\
S4 vs S3 & 1.67 & 4 & 0.62 & 0.972 & No \\
S3 vs SI & 21.67 & 4 & 8.02 & $<0.001$ & Yes \\
S3 vs S2 & 9.17 & 4 & 3.39 & 0.097 & No \\
S2 vs SI & 12.5 & 4 & 4.63 & 0.013 & Yes \\
\hline
\end{tabular}

Appendix 3 Pair wise comparison (Tukey test) for factor drought stress

\begin{tabular}{llllll}
\hline Comparison & $\begin{array}{l}\text { Diff. of } \\
\text { means }\end{array}$ & $\mathbf{P}$ & $\mathbf{Q}$ & $\mathbf{P}$ & $\mathbf{p}<0.050$ \\
\hline C vsW3 & 17.5 & 4 & 6.48 & $<0.00 \mathrm{I}$ & Yes \\
C vsW2 & 16.67 & 4 & 6.17 & $<0.00 \mathrm{I}$ & Yes \\
C vsWI & 8.33 & 4 & 3.08 & 0.15 & No \\
WI vsW3 & 9.17 & 4 & 3.39 & 0.097 & No \\
WI vsW2 & 8.33 & 4 & 3.08 & 0.15 & No \\
W2 vsW3 & 0.83 & 4 & 0.31 & 0.996 & No \\
\hline
\end{tabular}

Mean daily germination (on the basis of cumulative germination percentage) increased with increasing seed size class and decreased with increasing drought stress level (Figure 2A). In general, relative water content (RWC) showed a fluctuating pattern along the drought stress as well as size class gradient (Figure 2B). Maximum value of RWC (52.9\%) was reported for very large seed ( $\mathrm{S}_{4}$ size class) at -0.6 $\mathrm{MPa}$ drought stress level, while minimum value of RWC (33.1\%) was reported for $\mathrm{S}_{1}$ size class at $-0.6 \mathrm{MPa}$ drought stress level (Figure $2 \mathrm{~B}$ ).

Table 2 Effect of seed size and drought stress on initiation of seed germination in $\mathrm{Q}$. leucotrichophora.

\begin{tabular}{lllll}
\hline Drought stress level $(\mathbf{M P a})$ & \multicolumn{5}{l}{ Seed size class } \\
\hline & $\mathrm{I}$ & 2 & 3 & 4 \\
0 & 21 & 23 & 21 & 25 \\
-0.3 & 22 & 22 & 23 & 23 \\
-0.6 & 27 & 22 & 22 & 21 \\
-0.9 & 23 & 23 & 22 & 22 \\
\hline
\end{tabular}

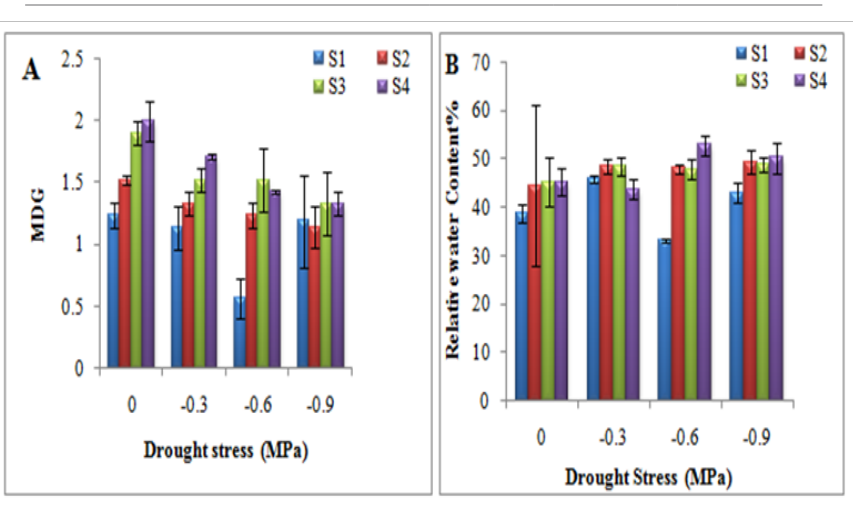

Figure 2 Effect of seed size and drought stress on mean daily germination (MDG) (A). Relative water content (RWC) of Q. leucotrichophora (B).

\section{Effect of seed size on early seedling growth}

Seedling dry weight was inversely related to water stress. At each size class, fresh and dry weight of seedlings generally reduced with increasing water stress (Figure 3A-3B). At each water stress level, maximum fresh and dry weight of seedlings was recorded in highest seed size class. In terms of seedling dry weight, differences between size class and drought stress level were significant. The effect of size class also depend on drought stress level resulting in a statistically significant interaction between seed size class and drought stress level (Appendix 4). Pair wise comparison between size classes showed that except between S3 and S2 seedling dry mass showed significant difference (Appendix 5) while between drought stress levels differences in seedling dry weight were significant except between W1 (-0.3 MPa) and W2 (-0.6 MPa) (Appendix 6). Seedling vigor index increased with increase in size class. Size class 4 showed maximum vigor index at all drought stress levels (Table 3). In general, in small seed size class, the vigor index decreased with increasing water stress while in large seed size class the vigor index decreased up to -0.6 MPa drought stress and then decreased in highest water stress level. The results presented indicated that fresh and dry weights were affected by drought stress in all size classes however; maximum reduction was recorded in small size class (Figure 4A-4B). 

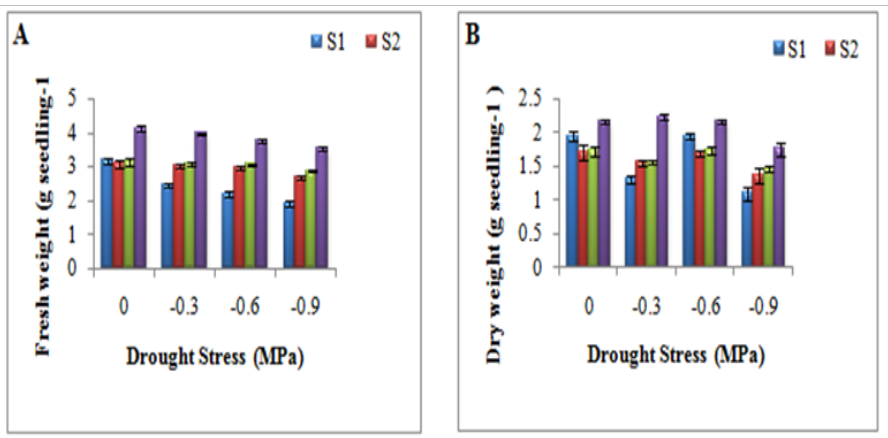

Figure 3 Fresh (A) and Dry weight (B) of Q. leucotrichophora seedlings as affected by seed size and water stress.

Appendix 4 Analysis of variance for seedling dry weight of $Q$. leucotrichophora as affected by seed size and drought stress.

\begin{tabular}{llllll}
\hline Source of Variation & DF & SS & MS & F & P \\
\hline Size class & 3 & 2.12 & 0.71 & 48.26 & $<0.001$ \\
$\begin{array}{l}\text { Drought stress } \\
\begin{array}{l}\text { Size class x drought } \\
\text { stress }\end{array}\end{array}$ & 3 & 1.33 & 0.44 & $30.4 \mathrm{I}$ & $<0.00$ I \\
Residual & 9 & 0.62 & 0.07 & 4.69 & $<0.001$ \\
Total & 32 & 0.47 & 0.01 & & \\
& 47 & 4.54 & 0.09 & &
\end{tabular}

Appendix 5 Pair wise comparison (Tukey test) for factor size class

\begin{tabular}{llllll}
\hline Comparison & Diff. of means & $\mathbf{P}$ & $\mathbf{Q}$ & $\mathbf{p}$ & $\mathbf{p}<0.050$ \\
\hline S4 vs SI & I.4I & 4 & 40.85 & $<0.00 \mathrm{I}$ & Yes \\
S4 vs S2 & $0.9 \mathrm{I}$ & 4 & $26.4 \mathrm{I}$ & $<0.00 \mathrm{I}$ & Yes \\
S4 vs S3 & $0.8 \mathrm{I}$ & 4 & 23.45 & $<0.100$ & Yes \\
S3 vs SI & 0.6 & 4 & 17.4 & $<0.100$ & Yes \\
S3 vs S2 & 0.1 & 4 & 2.96 & 0.176 & No \\
S2 vs SI & 0.49 & 4 & 14.44 & $<0.100$ & Yes \\
\hline
\end{tabular}

Appendix 6 Pair wise comparison (Tukey test) for factor drought stress

\begin{tabular}{llllll}
\hline Comparison & Diff. of means & $\mathbf{P}$ & $\mathbf{Q}$ & $\mathbf{p}$ & $\mathbf{p}<0.050$ \\
\hline C vsW3 & 0.62 & 4 & 18 & $0.00 \mathrm{I}$ & Yes \\
C vsW2 & 0.38 & 4 & 10.99 & $0.00 \mathrm{I}$ & Yes \\
C vsWI & 0.25 & 4 & 7.35 & 0.1 & Yes \\
WI vsW3 & 0.37 & 4 & 10.65 & 0.1 & Yes \\
WI vsW2 & 0.13 & 4 & 3.64 & 0.068 & No \\
W2 vsW3 & 0.24 & 4 & $\mathrm{I} .01$ & 0.1 & Yes \\
\hline
\end{tabular}

Table 3 Seedling Vigor Index (SVI) of Q. leucotrichophora seeds as affected by seed size and drought stress.

\begin{tabular}{lllll}
\hline Seed size class & \multicolumn{4}{l}{ Drought stress level $(\mathbf{M P a})$} \\
& 0 & -0.3 & -0.6 & -0.9 \\
SI & 73.1 & 52.4 & 29 & 32.7 \\
S2 & 94.6 & 72.4 & 68.8 & 54.4 \\
S3 & 129.4 & 83.2 & 87.4 & 67.7 \\
S4 & 157.5 & 133.8 & 92 & 81.7 \\
\hline
\end{tabular}

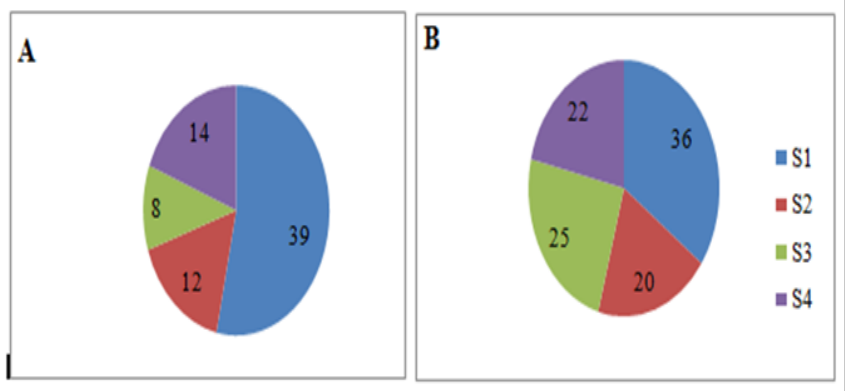

Figure 4 Fresh (A) and dry (B) weight percent reduction as affected by seed size in $\mathrm{Q}$. leucotrichophora seedlings.

\section{Response breadth}

In terms of germination percentage, maximum response breadth value was recorded for seed size class 2 and minimum value was recorded for size class 1 while in terms of dry weight maximum response breadth value was observed for size class 3 and minimum for size class 1 (Figure 5A-5B) indicating that small seeds were affected more severely by drought stress as compared to large seeds.

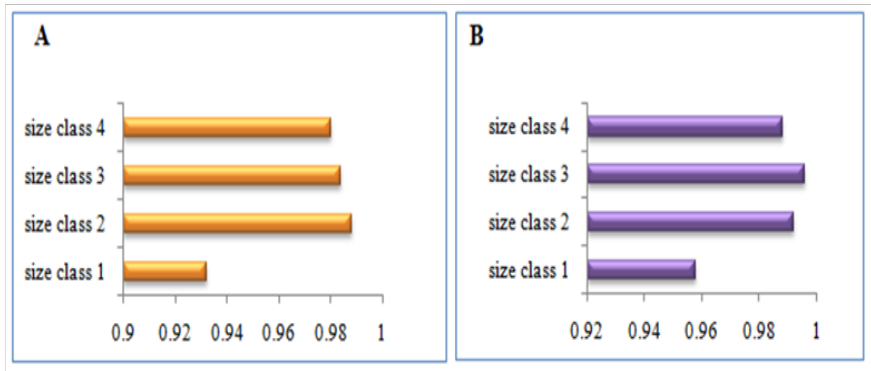

Figure 5 Response breadths in terms of seed germination $(A)$ and in terms of seedling dry weight (B).

\section{Discussion}

Seed size in $Q$. leucotrichophora significantly affected both germination and early growth of seedlings. Very large sized seeds recorded highest seed germination (47-70\%) followed by large (47$67 \%$ ), medium (40-55\%) and small seeds $(20-43 \%)$. The higher germination percentage in large seeds as compared to medium and small seeds could be attributed to availability of more food reserve in large seeds than in medium and small sized seeds. Similar observations have been made and it was reported that seeds with large dimensions are likely to have large embryo which enhances germination ability. ${ }^{33,34}$ It was also reported that size of seed has a strong influence on germination as well as growth and biomass increment of a plant. ${ }^{35}$ In contrast to this it was observed that the medium sized seeds produced better germination than those of smaller and bigger ones. ${ }^{36}$

In the present study, averaged over all seed sizes, increased drought stress induced by decreasing osmotic potential of germinating substrate decreased final germination percentage (Table 4). Final germination percentage was reduced $18 \%$ while seedling dry mass was reduced by $27 \%$ as a result of increasing drought stress from 0 to $-0.9 \mathrm{MPa}$. There were differences in the final germination percentage of seed size depending upon the drought stress intensity and large seeds exhibited $23 \%$ greater germination than small seeds regardless of water stress (Table 4). It was reported that large seeds with higher germination percentage in normal and stress conditions may be related to privileged water uptake. ${ }^{37}$ In oak species seed size variability is a common feature and could affect seed germination and seedling 
growth. Response breadth value for germination percentage also indicated that germination inhibition due to drought stress was more pronounced in small seeds (narrow response breadth) as compared to large seeds.

In contrast to germination percentage, the germination rate decreased with increasing seed size and drought stress (Table 4). Usually small seeds gain an advantage over large seeds by germinating faster and having a greater relative growth rate. ${ }^{38}$ At the time of sowing, inadequate soil moisture results in irregular seed germination and unsynchronized seedling emergence, thereby affecting the establishment of a stand. ${ }^{39}$ In the present study, seedling growth under unstressed condition (control) was maximum and minimum under high water stress $(-0.9 \mathrm{MPa})$ indicating that increasing drought stress resulted in decreased seedling growth (Table 4). Seedling vigor index increased with increasing seed size and decrease with increasing drought stress level (Table 4). It was also stated that seed size has been associated with early seedling vigor. ${ }^{40}$

Percent weight reduction indicated that large seeds were less affected by drought stress as compared to small seeds (Table 4). These finding were also supported by response breadth values recorded for seedling dry mass. Large seed size class $\left(\mathrm{S}_{3}\right)$ showed broad response breadth as compared to small seeds. Large seeds contain more mineral nutrients and carbon-based reserves than small seeds. Young seedlings from large seeds are therefore more likely to tolerate adverse conditions. It was suggested that the various benefits of large seededness could have a single underlying mechanism the "reserve effect". ${ }^{41}$ This extra metabolic resource in large seeds could remain uncommitted and could then serve to support unpredictable levels of carbon deficits caused by drought, shade or herbivory.

The variation among size classes showed that the germination stress tolerance index (GSI) decreased with increase in drought stress level (Table 4). However, large seeds performed better than small Table 4 Means ( \pm standard error) comparison of seed size, drought stress level and their interaction on the studied parameters

\begin{tabular}{|c|c|c|c|c|c|c|c|c|c|c|}
\hline & \multicolumn{10}{|c|}{ Parameters } \\
\hline & GP (\%) & GR & FW (g) & DW (g) & RWC (\%) & sVI & GSI & SDSI & FWPR & DWPR \\
\hline \multicolumn{11}{|c|}{ Seed size class } \\
\hline SI & $33.2 \pm 8.63$ & $0.49 \pm 0.21$ & $2.43 \pm 0.31$ & $1.45 \pm 0.21$ & $40.70 \pm 3.88$ & $46.8 \pm 10.15$ & $69.3 \pm 13.56$ & $66.0 \pm 5.5 \mathrm{I}$ & $31.3 \pm 4.91$ & $34 \pm 5.51$ \\
\hline S2 & $46.7 \pm 1.65$ & $0.32 \pm 0.07$ & $2.94 \pm 0.11$ & $1.53 \pm 0.08$ & $48.68 \pm 0.35$ & $73.0 \pm 9.46$ & $79.60 \pm 3.92$ & $87.0 \pm 3.51$ & $6.3 \pm 3.38$ & $|3.0 \pm 3.5|$ \\
\hline S3 & $55.3 \pm 5.69$ & $0.36 \pm 0.15$ & $3.04 \pm 0.07$ & $1.58 \pm 0.06$ & $48.49 \pm 0.27$ & $91.9 \pm 13.2$ & $77.0 \pm 3.6 \mathrm{I}$ & $89.0 \pm 2.52$ & $4.66 \pm 2.18$ & $11.0 \pm 2.52$ \\
\hline S4 & $56.7 \pm 5.31$ & $0.32 \pm 0.13$ & $3.85 \pm 0.15$ & $2.02 \pm 0.15$ & $49.00 \pm 2.71$ & $116.2 \pm 14.77$ & $75.2 \pm 6.71$ & $86.3 \pm 6.44$ & $9.3 \pm 3.17$ & $8.66 \pm 6.44$ \\
\hline \multicolumn{11}{|c|}{ Drought stress level (MPa) } \\
\hline 0 & $58.67 \pm 3.20$ & $0.33 \pm 0.13$ & $3.37 \pm 0.39$ & $1.90 \pm 0.23$ & $43.49 \pm 2.16$ & $113.6 \pm 18.65$ & $100 \pm 0.0$ & $100 \pm 0.0$ & 0 & 0 \\
\hline-0.3 & $49.9 \pm 6.59$ & $0.59 \pm 0.13$ & $3.13 \pm 0.32$ & $1.67 \pm 0.13$ & $46.7 I \pm 3.35$ & $85.4 \pm 17.3$ & $85.7 \pm 2.87$ & $87 \pm 6.93$ & $7.75 \pm 5.11$ & $13.0 \pm 6.93$ \\
\hline-0.6 & $42.5 \pm 12.57$ & $0.38 \pm 0.16$ & $2.99 \pm 0.19$ & $1.60 \pm 0.08$ & $45.53 \pm 1.36$ & $69.3 \pm 14.3$ & $70.2 \pm 8.48$ & $84.7 \pm 3.90$ & $11.75 \pm 6.54$ & $15.2 \pm 3.90$ \\
\hline-0.9 & $40.80 \pm 4.56$ & $0.19 \pm 0.03$ & $2.75 \pm 0.52$ & $\mathrm{I} .4 \mathrm{I} \pm 0.28$ & $47.90 \pm 1.28$ & $59.1 \pm 8.42$ & $69.5 \pm 1.04$ & $74.5 \pm 6.29$ & $19.2 \pm 7.03$ & $25.5 \pm 6.29$ \\
\hline
\end{tabular}

\section{Conclusion}

This study reveals that seed size is a life history trait relevant for germination and seedling growth in Q. leucotrichophora. Seeds play a vital role in natural and artificial regeneration. In natural exposed conditions where drought is a major limiting obstacle to the regeneration, seeds which can tolerate high water stress have better chance to germinate. Compared to small seeds, large seeds tend to have greater germination percentage (47\%) and greater seedling dry seeds. Many reports indicated that GSI can be used as screening criteria for stress tolerance. ${ }^{42}$ However, it was also suggested that germination criteria did not reflect stress tolerance in plants, but indicate seed quality differences. ${ }^{43}$ The variation in performance of $Q$. leucotrichophora determined by early seedling growth as fresh and dry weight indicated that seedling growth is a reliable and efficient procedure for screening seed size for drought tolerance. Although fresh and dry weight of seedlings decreased with the increase in drought stress level, different size classes showed difference in their responses. There are reports which in agreement with the present study indicating that drought stress severely reduce the biomass of plants, but the seeds having higher potential to maintain the higher growth under stress condition are drought tolerant. In the present study, large seeds showed higher seedling dry weight stress tolerance index (SDSI) as compared to small seeds (Table 4). These results indicated that larger seeds have the ability to store greater amount of carbohydrate in their endosperm or cotyledons than small seeds. ${ }^{44}$ This may enable early development of an enlarged resource gathering system (root or photosynthetic tissue) to produce a faster growing plant ${ }^{45}$ and large seeds can withstand unfavorable environmental conditions over a long period of time, while smaller seeds under the same condition deplete their reserves in the process of respiration and physiological rearrangements.

In Central Himalaya, the climate is characterized by the monsoon pattern of rainfall, with about three fourth of the annual rainfall occurring during mid June to mid September (rainy season). The seed fall in Q. leucotrichophora takes place during December to January which is not synchronized with rainy season; therefore the seeds may often be subjected to prolonged dry spell in the field. Under drought stress conditions, large seeds in $Q$. leucotrichophora have higher benefits in germination compared to small seeds. Therefore higher germination percentage from large seeds may be beneficial and should give an advantage in establishment of plants under dry soil conditions. give an advartion the interaction on the studied parameters mass $(1.55 \mathrm{~g})$ at highest drought stress level. Small seed however, may gain an advantage over larger seeds by germinating faster (as indicated by higher germination rate). The seed size is a considerable and significant factor in the germination and early stage of plant growth. Different size of seeds having different levels of carbohydrates and other food storage may be one factor which influences the expression of germination and growth of plants. Present study suggested that large seeds can withstand unfavorable environmental conditions over 
a long period of time, while smaller seeds under the same conditions deplete their reserves in the process of respiration and physiological rearrangements. The overall results showed that the seed grading is an essential step to improve the quality of nursery stock as well as their performance at field conditions. Therefore, large sized seeds should be used in direct seeding and nursery preparation to get higher and quicker seed germination and early seedling growth and establishment in Q. leucotrichophora.

\section{Acknowledgements}

We are thankful to Head, Department of Botany, DSB Campus, Nainital for providing necessary lab facilities.

\section{Conflict of interest}

Author declares there is no conflict of interest.

\section{References}

1. Nwoboshi LC. Tropical silviculture principle and techniques. Ibadan University press publishing house, Nigeria; 1982. p. 330

2. Shahi C, Vibhuti, Bargali K, et al. How seed size and water stress affect the seed germination and seedling growth in wheat varieties. Curr Agric Res. J 2015;3(1):60-68.

3. Gunaga RP, Doddabasava, Vasudeva R. Influence of seed size on germination and seedling growth in. Karnataka J Agri Sci. 2011;24(3):415-416.

4. Oni O, Bada SO. Effects of seed size on seedlings vigour in Idigbo (Terminalia ivorensis A. Chev.). J Trop For Sci. 1992;4(3):215-224.

5. Aiken GE, Springer TL. Seed size distribution, germination and emergence of 6 switch grass cultivars. J of Range Manage. 1995;48(5):455-458.

6. Zhang J, Maun MA. Sand burial effects on seed germination, seedling emergence and establishment of Panicum virgatum. Holarct Ecol.1990;13(1):56-61.

7. Winn AA. Ecological and evolutionary consequences of seed size in Prunella vulgaris. Ecology. 1988;69(5):1537-1544.

8. Wulff RD. Seed size variation in Desmodium paniculatum II Effects on seedling growth and physiological performance. $J$ Ecol. 1986;74(1):99-114

9. Marshell DL. Effect of seed size on seedling success in three species of Sesbania (Fabaceae). Am J Bot. 1986;73(4):457-464.

10. Stanton ML. Seed variation in wild radish: effect of seed size on components of seedling and adult fitness. Ecology. 1984;65(4):1105-1112.

11. Khan ML, Shankar U. Effect of seed weight, light regime, and substratum microsite on germination and seedling growth of Quercus semiserrata Roxburghii. Trop Ecol. 2001;42(1):117-125.

12. Roach DA. Variation in seed and seedling size in Anthoxanthum odoratum. Am Midl Nat. 1987;117(2):258-264.

13. Harker KN, Donovan TO, Smith EG, et al. Seed size and seedling rate effects on canola emergence, development, yield and seed weight. Can J of Plant Sci. 2015;95(1):1-8.

14. Stoehr MU, Farmer RH.Genetic and environmental variance in cone size, seed yield and germination properties of black spruce clones. Can J For Res. 1986;16(5):1149-1151.

15. Tripathi RS, Khan ML. Effects of seed weight and microsite characteristics on germination and seedling fitness in two species of Quercus in a subtropical wet hill forest. Oikos. 1990;57(3):289-296.

16. Kramer PJ, Kozlowski TT. Physiology of trees. Mc Graw- Hill, New York, USA; 1980
17. Hegarty TW. The physiology of seed hydration and dehydration, and the relation between water stress and control of germination: a review. Plant Cell Environ. 1978;1(2):101-109.

18. Baskin CC, Baskin JM. Seeds: Ecology, Biogeography and Evolution of dormancy and germination. Academic Press, New York, USA; 1998. p. xiv +666

19. Lopez M, Humara JM, Casares A, et al. The effect of temperature and water stress on laboratory germination of Eucalyptus globules Labill. Seeds of different sizes. Ann For Sci. 2000;57(3):245-250.

20. Bargali K, Bargali SS. Germination capacity of seeds of leguminous plants under water deficit conditions: implication for restoration of degraded lands in Kumaun Himalaya. Trop Ecol. 2016;57(3):445-453.

21. Vibhuti, Shahi C, Bargali K, et al. Seed germination and seedling growth parameters of rice (Oryza sativa L.) varieties as affected by salt and water stress. Indian J Agric Sci. 2015;85(1):102-108.

22. Uniyal RC, Nautiyal AR. Seed germination and seedling extension growth in Ougeinia dalbergioides, under water and salinity stress. New For. 1998;16:265-272.

23. Bargali K, Joshi B, Bargali SS, et al. Diversity within Oaks. Int Oaks. 2014;25:57-70.

24. Bargali K, Joshi B, Bargali SS, et al. Oaks and the biodiversity they sustain. Int Oaks. 2015;26:65-76.

25. Thadani R, Ashton MS. Regeneration of banj oak (Quercus leucotrichophora A. camus) in the Central Himalaya. For Ecol Manage. 1997; 78:217-224

26. Bargali K, Bisht P, Khan A, et al. Diversity and regeneration status of tree species at Nainital catchment,Uttarakhand, India. Int $J$ Biodivers Conserv. 2013;5(5):270-280.

27. ISTA. Handbook for seedling evaluation. International Seed Testing Association, Zurich, Switzerland; 1993. p. 232.

28. Abdul-Baki AA, Anderson JD. Viability and leaching of sugars from germinating barley. Crop science. 1970;10(1):31-34.

29. Sumithra K, Jutur PP, Carmel BD, et al. Salinity -induced changes in two cultivars of Vigna radiata: responses of ant oxidative and proline metabolism. Plant Growth Regu. 2006;50(1):11-22.

30. Ashraf MY, Akhtar K, Hussain F, et al. Screening of different accessions of three potential grass species from Cholistan desert for tolerance. Pak J Bot. 2006;38(5):1589-1597.

31. Levins R. Evolution in changing environments. Princeton University Press, Princeton, USA; 1968. p. 132.

32. Bargali K, Singh SP. Competitive abilities of Quercus leucotrichophora and Pinus roxburghii seedlings in relation to experiments variations in soil moisture availability. Trop Ecol. 1996;37:223-227.

33. Shaukat SS, Mustaq M, Siddiqui ZS. Effects of cadmium, chromium and lead on seed germination, early seedling growth and phenolic contents of Parkinsonia aculeate L. and Pennisatum americanum (L.) Schumann. Pak J Biol Sci. 1999;2(4):1307-1313.

34. Offiong MO. Variation in growth and physiological characteristics of Xylopia aethopica (Dunal) A. Rich from Akwa Ibom and cross river states, Ibadan, Nigeria; 2008;255.

35. Owah PW, Offiong MO, Udofia SI, et al. Effects of seed size on germination and early morphological and physiological characteristics of Gmelina arborea Rox. Afr Res Rev. 2011;5(6): 422-433.

36. Dar FA, Gera M, Gera N. Effect of seed grading on germination pattern of some multipurpose tree species of Jammu region. Indian For. 2002;128(5):509-512. 
37. Kaydan D, Yagmur M. Germination, seedling growth and relative water content of shoot in different seed sized of triticale under osmotic stress of water and $\mathrm{NaCl}$. Afr J Biotech. 2008;7(16):2862-2868.

38. Susko DJ, Cavers PB. Seed size effects and competitive ability in Thlaspi arvense L.(Brassicaceae). Botany. 2008;86(3):259-267.

39. Kanta C, Rao PB. Effect of water stress on seed germination and seedling growth in six medicinal plant species in Tarai region Uttarakhand. Bioscan. 2014;9(4):1383-1388.

40. Pepper-Gray E. Reduced Soybean seed size in 1996: will it make a difference? University of Illinois, Illinois, USA; 2002.

41. Westoby M, Leishman M, Lord J, et al. Comparative ecology of seed size and dispersal. Phil. Trans. Royal Society London, Series B. Biological Sciences. 1996;351(1315):1309-1318.
42. Ahmad S, Ahmad R, Ashraf MY, et al. Sunflower (Helianthus annuus $L$.) response to drought stress at germination and seedling growth stages. Pak J Bot. 2009;41(2):647-654.

43. Ashraf M, Oleary JW. Effect of drought stress on growth, water relations and gas exchange of two lines of sunflower differing in degree of salt tolerance. Int J Plant Sci. 1996;157(6):729-732.

44. Milberg P, Lamount BB. Seed /Cotyledon size and nutrient content play a major role in early performance of species on nutrient-poor soil. New Phytol. 1997;137(4):665-672.

45. Hewitt N. Seed size and shade tolerance: A comparative analysis of North American temperate trees. Oecologia. 1998;114(3):432-440. 